\title{
Prospecção arqueológica e sistemas geomorfológicos em áreas urbanas: o caso da estação Vila Prudente do metrô, São Paulo, SP
}

\author{
Rodolfo Alves da Luz*
}

\begin{abstract}
LUZ, R.A. Prospecção arqueológica e sistemas geomorfológicos em áreas urbanas: o caso da estação Vila Prudente do metrô, São Paulo, SP. R. Museu Arq. Etn., São Paulo, n. 21, p. 335-343, 2011.
\end{abstract}

Resumo: Visando orientar as prospecções arqueológicas na área da Estação Vila Prudente do Metrô de São Paulo foram realizadas investigações a respeito dos sistemas geomorfológicos envolvidos. Para tal, foi considerada a dinâmica natural de cada sistema geomorfológico e o tipo de ação antrópica que ali ocorreu durante a urbanização da área. Os resultados foram então espacializados, auxiliando assim na indicação de setores com maior probabilidade de ocorrência de vestígios arqueológicos. A pesquisa permitiu o reconhecimento das mudanças geomorfológicas de caráter antropogênico relacionadas ao processo de urbanização da região, e de como estas mudanças alteraram a disposição das camadas arqueológicas.

Palavras-chave: Geoarqueologia - Arqueologia urbana - Geomorfologia antropogênica.

\section{Introdução}

\begin{abstract}
arqueologia realizada em áreas urbanas é mais cara e difícil do que outros tipos de arqueologia, demandando investigações e estratégias de amostragem e prospecção específicas para determinar a natureza e extensão do registro arqueológico (Staski 2002). Neste estudo tratamos a cidade como um ambiente de estudo arqueológico, um ambiente singular que requer a aplicação de um conjunto de métodos de investigação
\end{abstract}

(*) Mestre em Geografia pela Universidade de São Paulo, Faculdade de Filosofia, Letras e Ciências Humanas, Dep. de Geografia.<rodolfo.luz@usp.br> arqueológica específicos. Estes métodos devem levar em consideração os contextos ambientais e históricos e o grau de preservação do solo (Juliani 1996).

A análise geomorfológica de uma área que é alvo de investigações arqueológicas é de fundamental importância para a análise do grau de preservação do solo. Além disso, ela proporciona um efetivo entendimento do contexto ambiental atual e pretérito da área, auxilia na contextualização do material arqueológico encontrado e, juntamente com a análise pedológica e estratigráfica, colabora na identificação das diferentes camadas arqueológicas existentes.

O grau de integridade do material arqueológico e sua manutenção em configurações 
Prospecção arqueológica e sistemas geomorfológicos em áreas urbanas: o caso da estação Vila Prudente do metrô, São Paulo, SP. R. Museu Arq. Etn., São Paulo, n. 21, p. 335-343, 2011.

urbanas só podem ser avaliados por meio de uma investigação geomorfológica retrospectiva, tendo em vista as modificações de alto impacto ocorridas durante a urbanização. No geral, estas modificações são materializadas na paisagem pelos cortes de talude no sistema vertente (morros e colinas) e aterros e modificações de canais no sistema fluvial (terraços fluviais, planícies de inundação e canais fluviais). Estas modificações de origem antrópica alteram significativamente a morfologia da área, seja devido à remobilização da cobertura pedológica e de parte do embasamento geológico nos morro e colinas, seja devido ao aterramento dos solos hidromórficos e sedimentos quaternários nas planícies fluviais, destruindo ou enterrando as possíveis camadas arqueológicas do local.

Portanto, o grau do impacto das intervenções antrópicas de caráter urbano em camadas subsuperficiais potencialmente arqueológicas dependerá do sistema geomorfológico no qual elas ocorrem: sistema vertente ou sistema fluvial. A análise prévia destes sistemas possibilita então a avaliação da potencialidade de ocorrência de vestígios em cada um deles, que pode ser então espacializado, gerando um zoneamento arqueológico da área de estudo. $\mathrm{O}$ zoneamento, além de indicar o potencial arqueológico da área investigada, auxilia na definição do tipo de investigação arqueológica necessária duran- te a prospecção, principalmente na definição da malha e da profundidade dos poços-testes e sondagens.

Este artigo mostra como esta análise foi realizada numa área densamente urbanizada, tendo como exemplo a prospecção arqueológica do Programa de Diagnóstico, Prospecção e Monitoramento Arqueológico das Obras de Implantação da Linha 02 / Verde do Metrô, Lote 8, São Paulo/SP (Estação Vila Prudente), trabalhos executados pela empresa Documento Arqueologia e Antropologia, sob coordenação da L.D. Erika Robrahn-Gonzalez (Fig. 1).

No local funcionou a Companhia Industrial Paulista de Papéis e Papelão (CIPA), fechada em 1993 e fundada, provavelmente, no início do século XX. Quando da chegada da equipe de pesquisa ao local as edificações da antiga indústria não haviam sido demolidas, sendo que as escavações foram realizadas diretamente sobre o piso das edificações da indústria.

\section{Materiais e métodos}

A partir da análise bibliográfica e cartográfica a respeito da geomorfologia e da geologia da área, foram identificados os sistemas geomorfológicos e os materiais superficiais (solos e embasamento
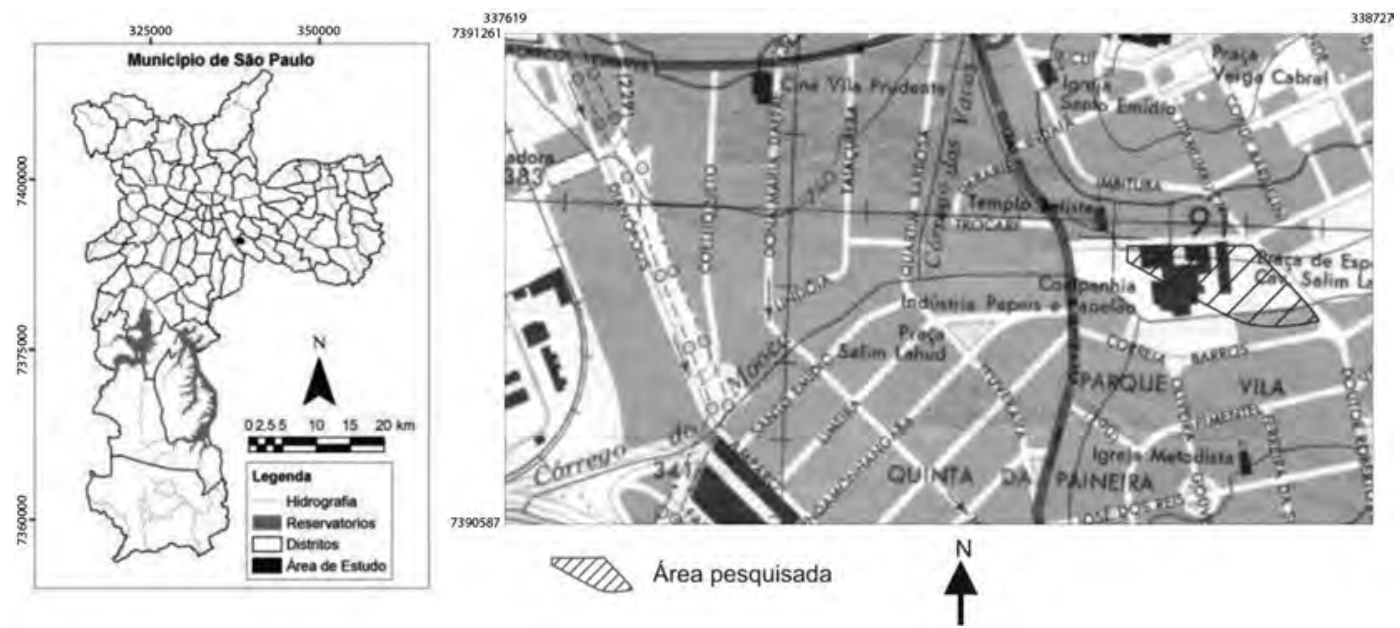

Fig. 1. Área de estudo em excerto da carta topográfica do IGC de 1971. 
geológico) associados a cada um deles. Isto possibilitou a elaboração de um zoneamento arqueológico prévio, tendo em vista a possibilidade de ocorrência e a integridade das potenciais camadas arqueológicas de cada sistema. Este estudo prévio foi complementado e validado nos trabalhos de campo.

O objetivo desta análise foi de, a partir do entendimento dos sistemas geomorfológicos envolvidos e dos impactos que eles sofreram durante a urbanização, identificar a existência e o grau de preservação de camadas arqueológicas, orientando assim a prospecção arqueológica em campo.

Foram então realizadas escavações até as camadas estéreis do ponto de vista arqueológico, por meio de malhas de poços-teste (Fig. 2) e de sondagens nos locais de maior detalhamento dos materiais pedológicos e sedimentológicos (Fig. 3).

A prospecção arqueológica ocorreu entre nov/07 e mar/08. Foram escavados poços-teste em uma malha intercalada de $15 \mathrm{~m}$ x $15 \mathrm{~m}$, reduzida para $10 \mathrm{~m}$ nos locais de impacto direto e definitivo da obra (Fig. 4).

\section{Resultados}

A área localiza-se na baixa vertente do compartimento geomorfológico denominado colinas tabulares de nível intermediário (Ab'Saber 1957), já em contato com a planície fluvial do córrego da Moóca, abrangendo assim dois sistemas geomorfológicos distintos (Fig. 5 e Fig. 6): 1) o sistema vertente relativo ao sopé da colina e; 2) o sistema fluvial relativo à planície fluvial do córrego da Moóca.

O sistema vertente é composto por solos desenvolvidos sobre os sedimentos terciários da Bacia Sedimentar de São Paulo (Formação Resen-

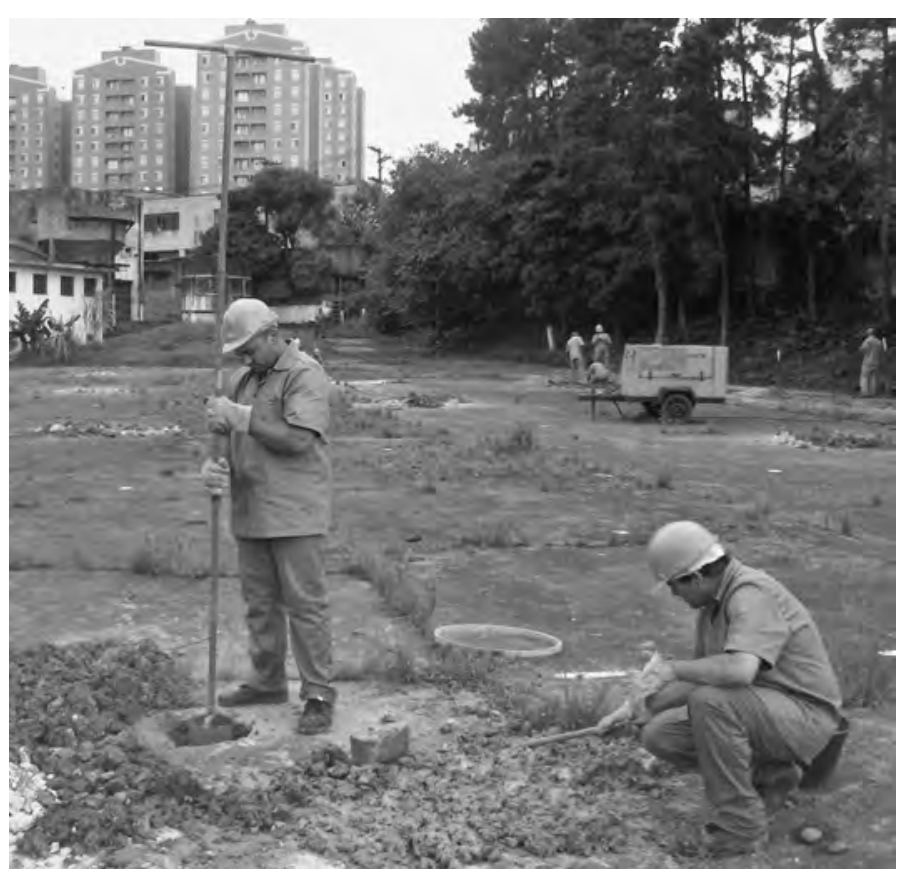

Fig. 2. Escavação de poço-teste.

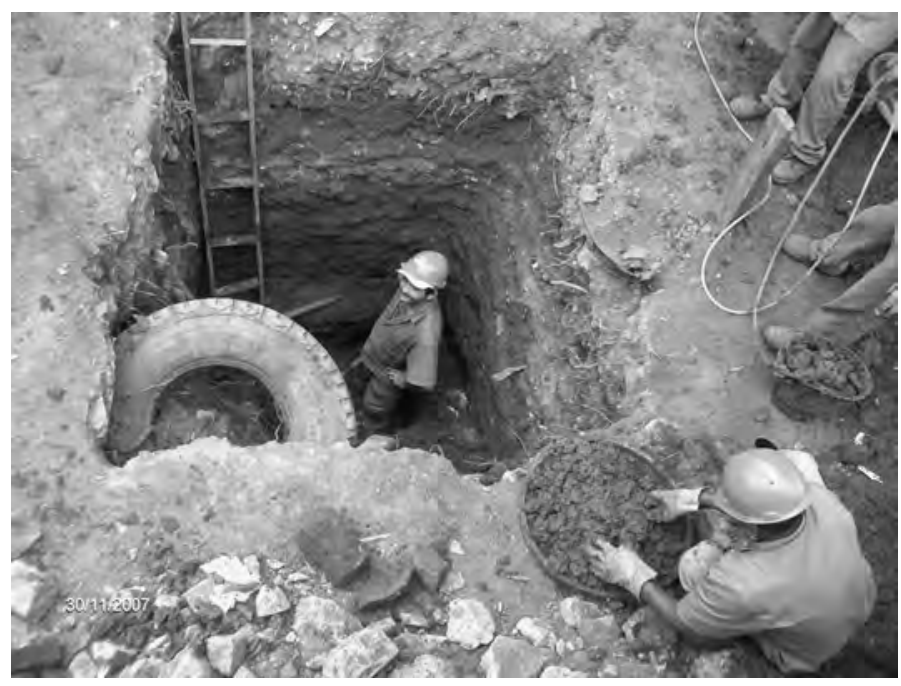

Fig. 3. Escavação de sondagem. 


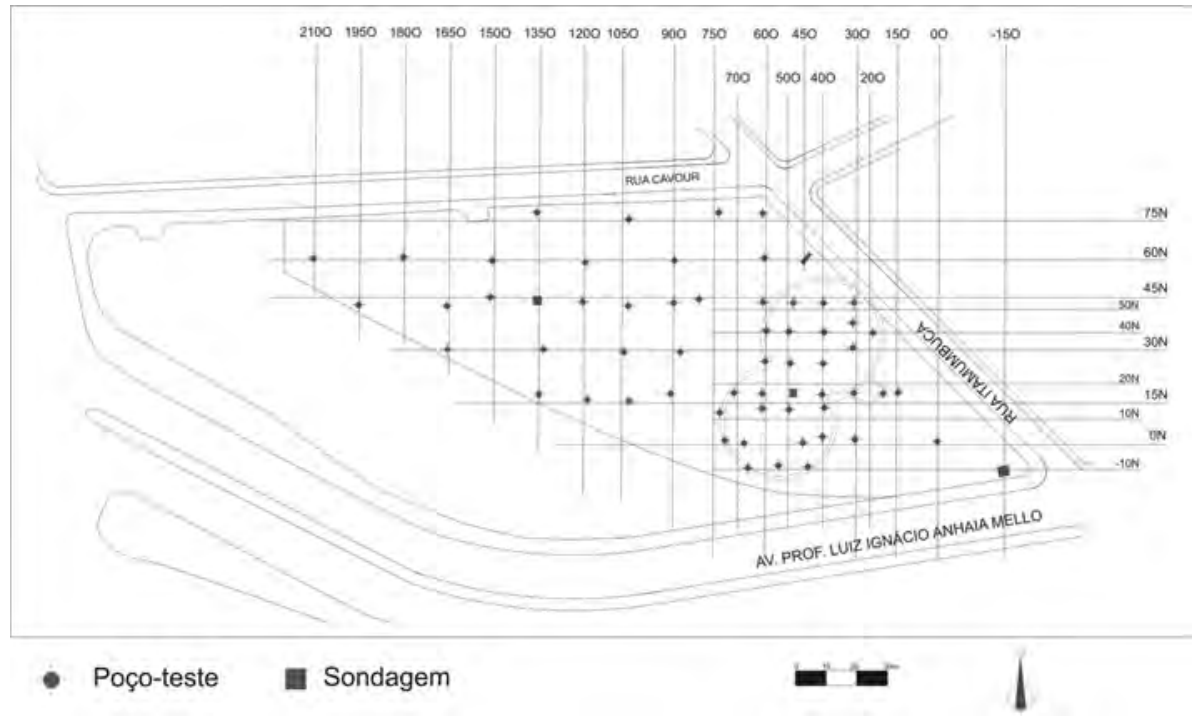

Fig. 4. Localização das escavações.

de), caracterizados por argilas siltosas e pouco arenosas de coloração variada, com predomínio dos tons vermelhos e roxos (PMSP-SVMA-SEMPLA 2002; Riccomini e Coimbra 1992; Vargas 1992).

O sistema fluvial é composto por depósitos tecnogênicos (aterros) sobre os sedimentos aluviais quaternários da planície fluvial do córrego da Moóca. O primeiro possui de 4 a 5 metros, e trata-se de materiais heterogêneos de diversas texturas e composição, como entulhos, pedregulhos e matéria orgânica (Fig. 7). Os sedimentos aluviais que estão abaixo destes depósitos tecnogênicos são compostos por argilas siltosas e arenosas com matéria orgânica (Fig. 8).

Os dados oriundos das escavações arqueológicas permitiram caracterizar os

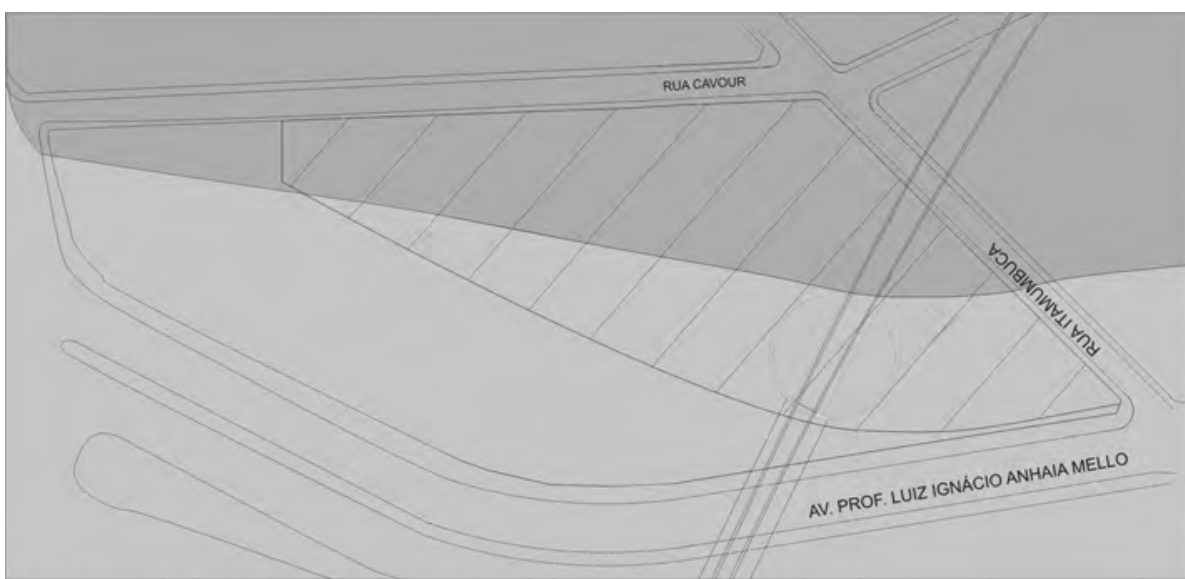

Sistema vertente (sopé da colina)

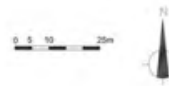

Sistema fluvial

\section{Área prospectada}

Fig. 5. Sistemas geomorfológicos identificados. 


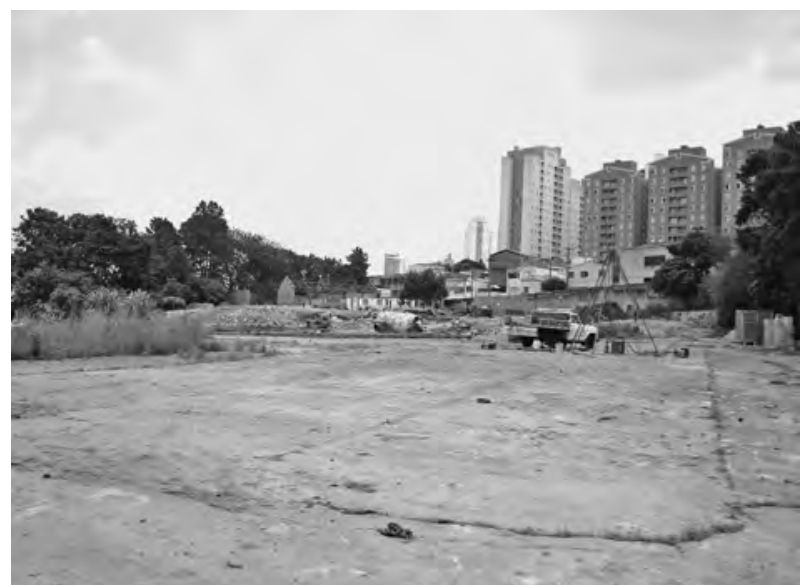

Fig. 6. Planície de inundação no primeiro plano e sopé da colina ao fundo.

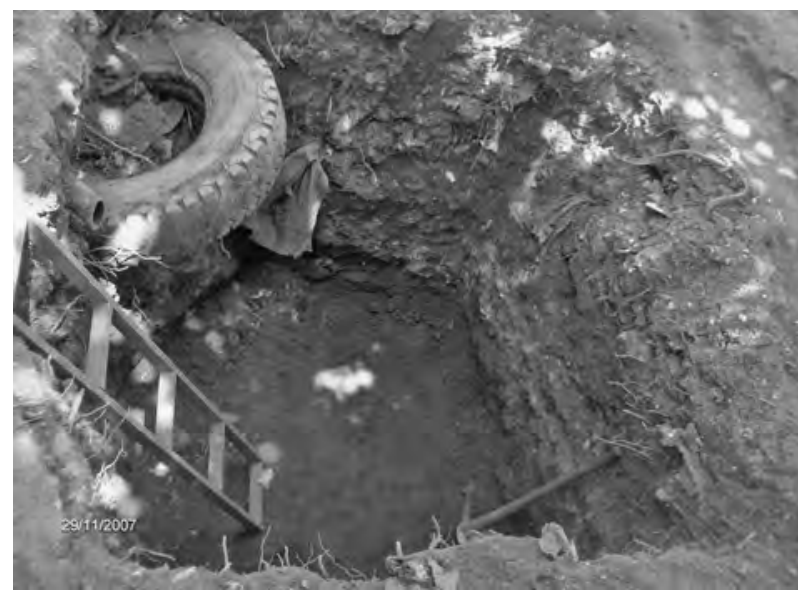

Fig. 7. Depósitos tecnogênicos em sondagem na planície fluvial.

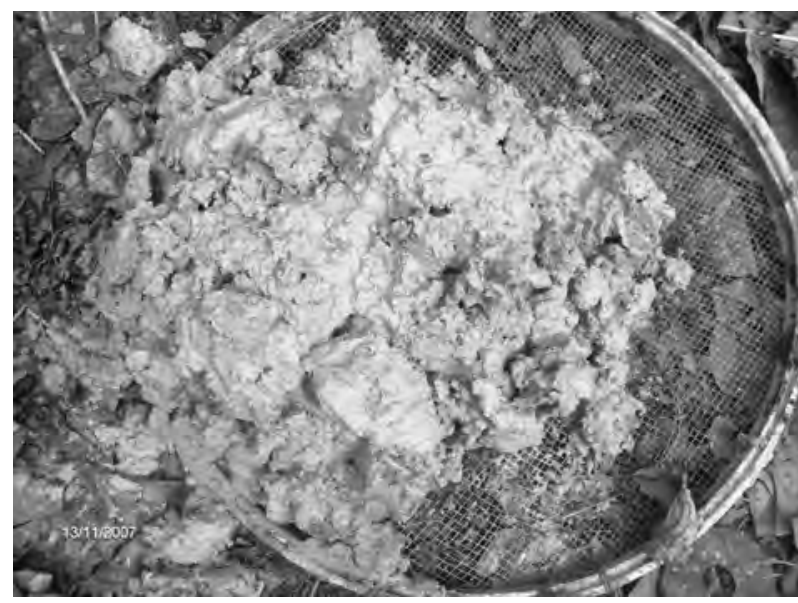

Fig. 8. Sedimentos quaternários da planície fluvial do córrego da Moóca. materiais superficiais e o grau de impacto antrópico de cada sistema geomorfológico da área. No sistema vertente foram encontradas duas situações: 1) solos preservados que apresentam a sequência típica de horizontes (A-B-C-R) sob finas camadas de aterro e; 2) solos decapitados por cortes de talude onde, por causa de terraplanagem anterior, o piso se encontrava diretamente sobre o embasamento geológico (Formação Resende).

O sistema fluvial é composto por sedimentos aluviais quaternários sob depósitos tecnogênicos (aterros). Os depósitos tecnogênicos chegam a mais de $3 \mathrm{~m}$ de espessura em alguns pontos e são compostos por entulhos misturados com materiais pedológicos e sedimentares semelhantes aos que são encontrados nos solos e no embasamento geológico do sistema vertente, demonstrando que possivelmente foram utilizados os materiais superficiais da própria vertente para aterrar a planície.

\section{Discussão}

A análise dos sistemas geomorfológicos envolvidos indica que os terrenos do sistema vertente são os mais propícios a assentamentos humanos, pois tratam de áreas próximas a um curso d'água (córrego da Moóca) com solos bem drenados e a salvo das inundações. Os terrenos associados ao sistema fluvial se referem a áreas frequentemente atingidas pelas cheias periódicas/anuais do córrego da Moóca apresentando, portanto, condições pouco propícias a assentamentos humanos.

As escavações arqueológicas permitiram caracterizar a cobertura pedológica e o embasamento geológico de cada sistema, complementando as infor- 
mações geomorfológicas. A análise integrada destes dados permitiu a identificação de setores com distintos graus de preservação de camadas arqueológicas e de possibilidade de ocorrência de vestígios (Fig. 9):

Zona 1 - Alto potencial arqueológico: Solos bem preservados sob finas camadas de aterros. Sopé da colina.

\section{Zona 2 - Baixo potencial} arqueológico: Horizontes pedológicos já retirados, com o piso diretamente sobre o embasamento geológico (Formação Resende). Terrenos no sopé da colina que sofreram cortes e terraplanagens.

Zona 3 - Médio potencial arqueológico: Sedimentos fluviais aterrados. A composição dos aterros (entulhos misturados aos solos e ao embasamento geológico do sistema vertente) indica que o material utilizado possivelmente foi retirado dos cortes de talude da Zona 2 (Fig.10).
Após o zoneamento da área segundo o seu potencial de ocorrência de vestígios arqueológico foi possível detalhar a prospecção na zona de maior potencial, por meio da redução da malha de poços-teste para $10 \mathrm{~m} \times 10 \mathrm{~m}$, que foi complementada por sondagens para maior detalhamento dos materiais superficiais (solos, aterros e embasamento geológico). Esta prospecção resultou na identificação de vestígios históricos no Horizonte A dos solos preservados da Zona 1.

Estes vestígios foram resgatados (Fig. 11 e Fig. 12) e remetem ao fim do século XIX e início do XX, até aproximadamente a década de 1920, diagnosticado pelos fragmentos de vidro soprado em molde duplo de uma garrafa de óleo de rícino e pelos fragmentos de faiança (Fig. 13).

O material resgatado abrange uma grande diversidade de itens, incluindo louça, grés, metais, vidro, moedas, botões, cerâmica, material construtivo, entre outros. Estes vestígios estão provavelmente associados

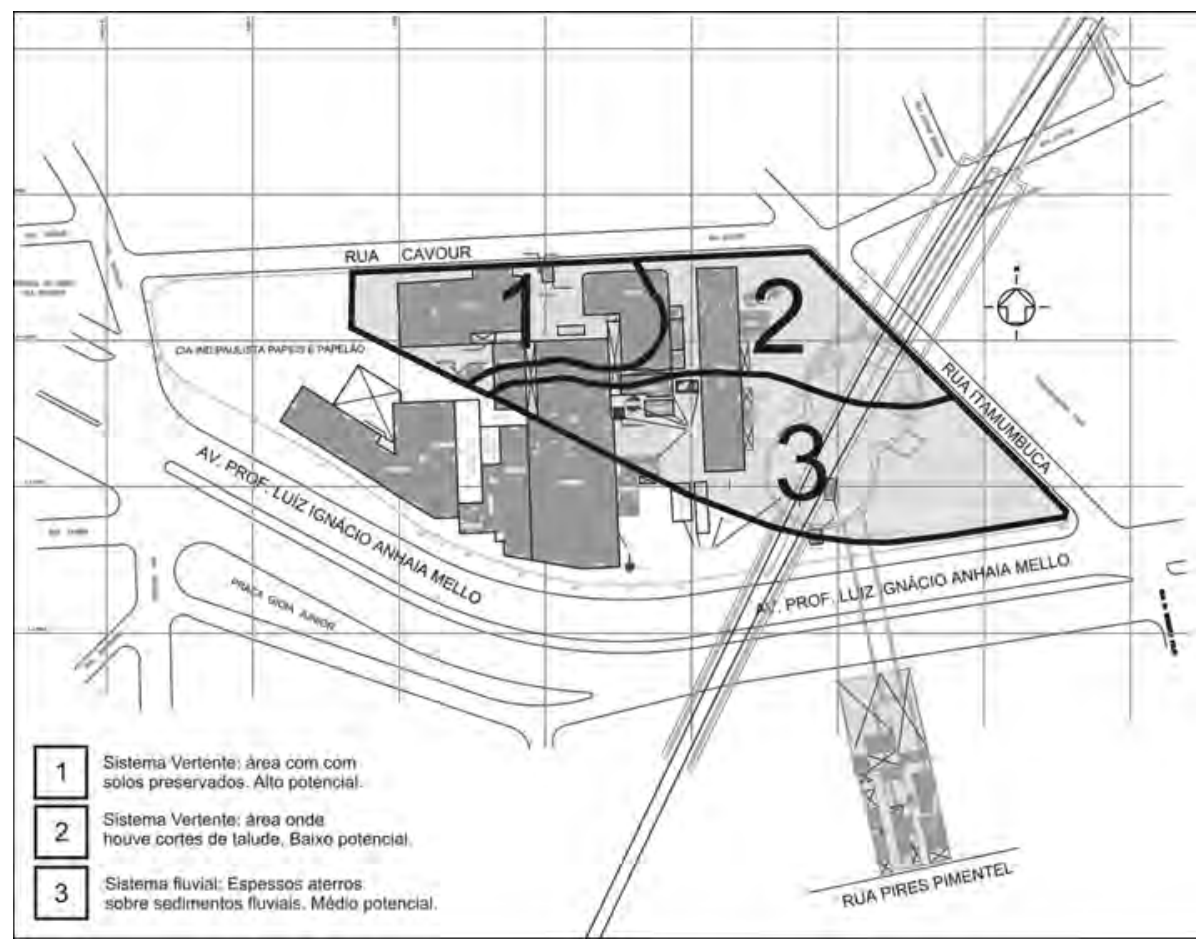

Fig. 9. Setores identificados e potencial arqueológico. 


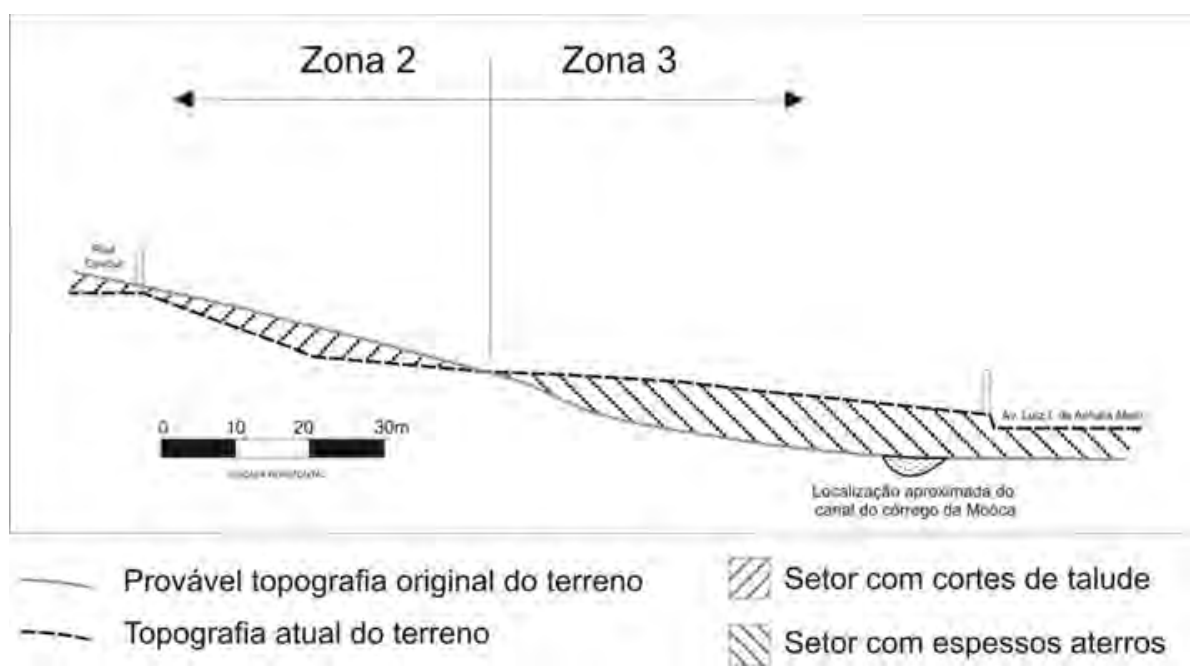

Fig. 10. Esboço topográfico indicando a provável configuração do terreno antes das intervenções urbanas (cortes de taludes e aterros).

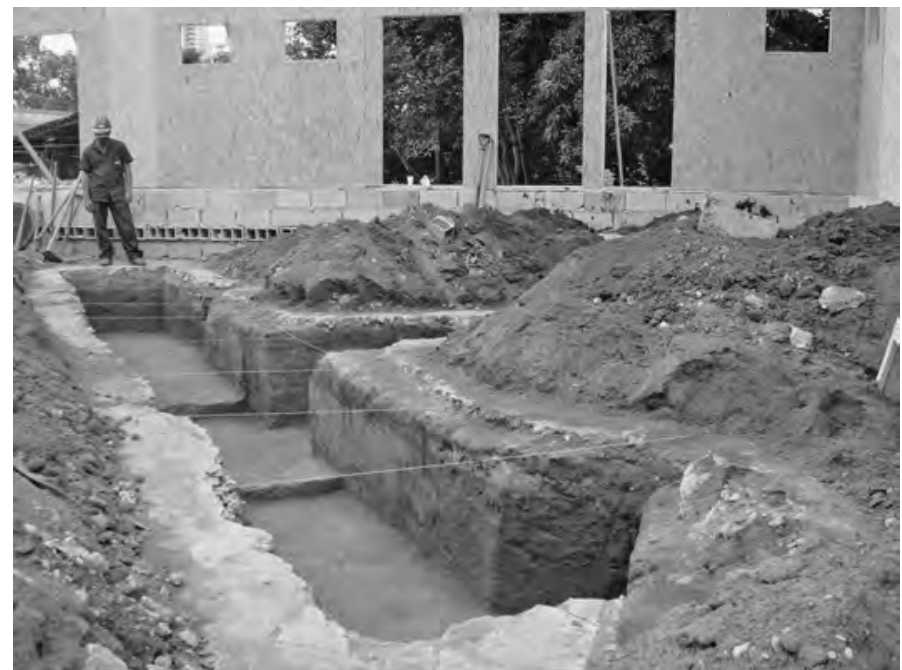

Fig. 11. Trincheira escavada durante o resgate arqueológico. as características naturais do terreno. $\mathrm{O}$ reconhecimento dos impactos antrópicos de alto grau ocorridos nestes sistemas naturais durante o processo de urbanização permitiu a identificação do grau de preservação das camadas arqueológicas da área.

A validade destas análises prévias foi comprovada durante a prospecção arqueológica, pois vestígios históricos foram encontrados justamente nas camadas pedológicas preservadas do sistema vertente, ou seja, na zona identificada como de maior potencial de arqueológico.

É preciso salientar que estes estudos prévios não eliminam a necessidade da intervenção arqueológica direta por meio de prospecções em toda a área, pois mesmo as áreas identificadas como de baixo potencial devem passar pela verificação em campo, que comprovará ou não o potencial previamente identificado.

A abordagem aqui apresentada, que considera as características originais dos sistemas geomorfológicos e as intervenções antrópicas 


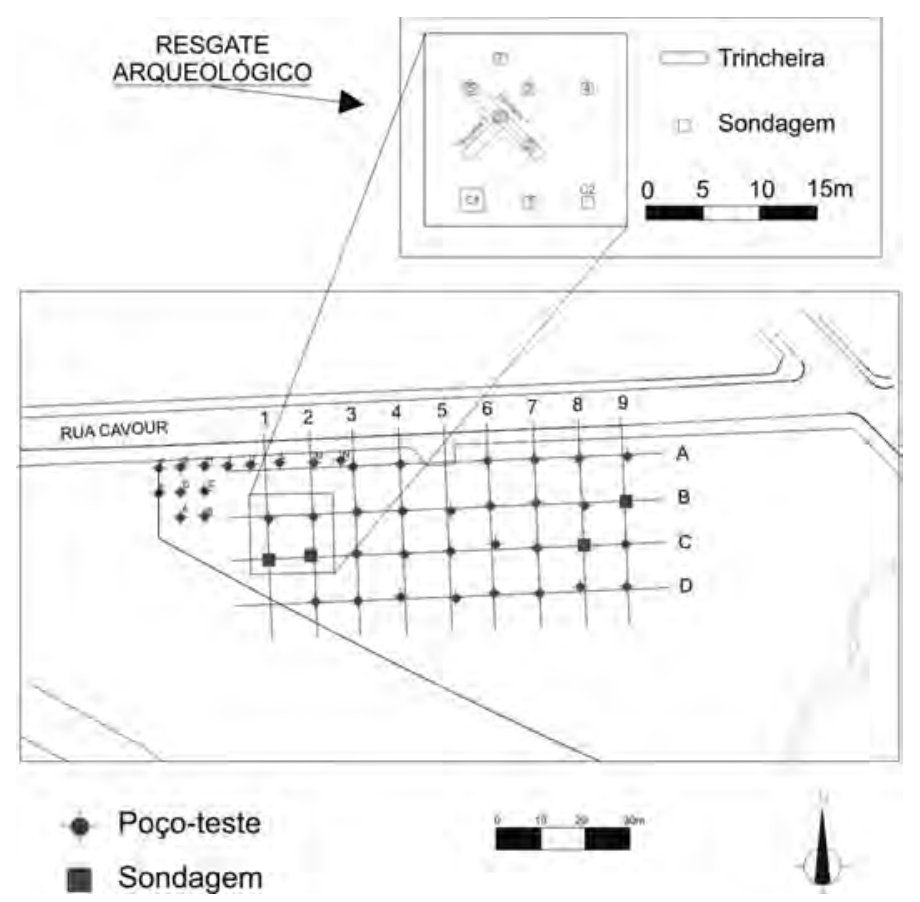

Fig. 12. Escavações na zona de alto potencial e resgate arqueológico.

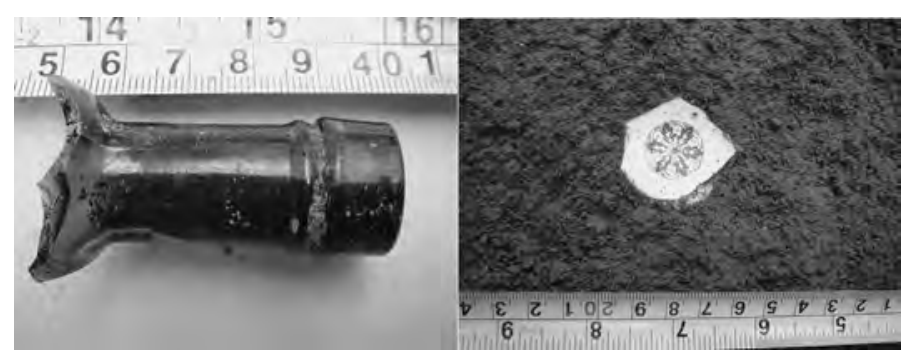

Fig. 13. Vestígios encontrados.

que estes sistemas sofreram ao longo da urbanização, pode orientar os esforços da prospecção arqueológica em áreas urbanas. Assim, zonas que apresentam camadas estéreis do ponto de vista arqueológico devem ser apenas caracterizadas como tal, fazendo com que as zonas de alto potencial possam ser mais detalhadas durante a prospecção.

\section{Agradecimentos}

À Documento Arqueologia e Antropologia S/S Ltda. empresa responsável pelo Programa de Diagnóstico, Prospecção e Monitoramento Arqueológico das Obras de Implantação da Linha 02/Verde do Metrô, Lote 8, São Paulo/SP e a todos os operários que ajudaram nas escavações. 
LUZ, R.A. Archaeological survey and geomorphological systems in urban areas: the example of a subway station in São Paulo, SP. R. Museu Arq. Etn., São Paulo, n. 21, p. 335-343, 2011.

Abstract: Geomorphological systems investigations were carried out to guide the archaeological prospection in a subway station in São Paulo. It was considered the natural dynamics of each geomorphological system and the anthropogenic activity that occurred during urbanization. The results were mapped and helped in the indication of sectors with highest probability of containing archaeological traces. The research allowed the identification of anthropogenic geomorphological changes related to urbanization, and how these changes modified the archaeological layers disposition.

Keywords: Geoarchaeology - Urban archaeology - Anthropogenic geomorphology.

\section{Referências bibliográficas}

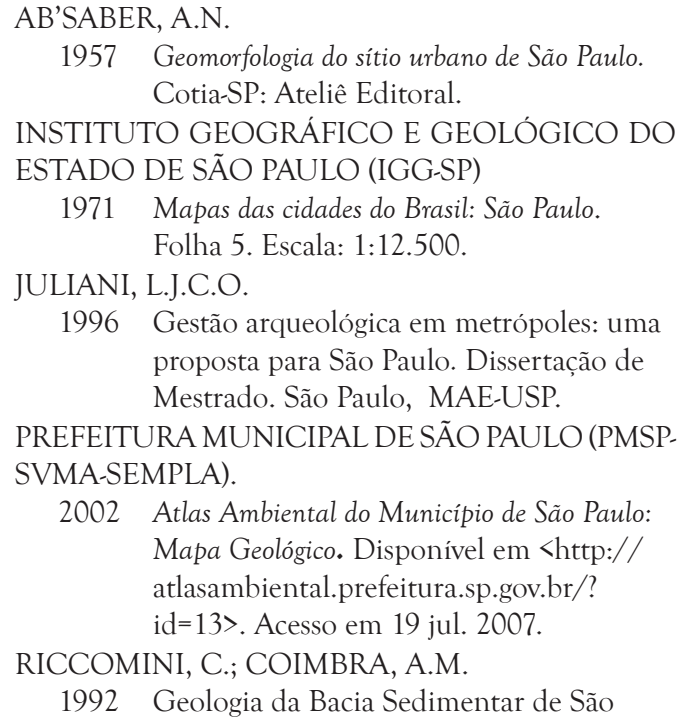

1957 Geomorfologia do sítio urbano de São Paulo. Cotia-SP: Ateliê Editoral.

\section{INSTITUTO GEOGRÁFICO E GEOLÓGICO DO} ESTADO DE SÃO PAULO (IGG-SP)

1971 Mapas das cidades do Brasil: São Paulo. Folha 5. Escala: 1:12.500.

JULIANI, L.J.C.O.

1996 Gestão arqueológica em metrópoles: uma proposta para São Paulo. Dissertação de Mestrado. São Paulo, MAE-USP.

PREFEITURA MUNICIPAL DE SÃO PAULO (PMSPSVMA-SEMPLA).

2002 Atlas Ambiental do Município de São Paulo: Mapa Geológico. Disponível em <http:// atlasambiental.prefeitura.sp.gov.br/? $\mathrm{id}=13>$. Acesso em 19 jul. 2007.

RICCOMINI, C.; COIMBRA, A.M.

1992 Geologia da Bacia Sedimentar de São

Paulo. In: Negro Jr., A.; Ferreira, A.A.; Alonso, U.R.; Luz, P.A.C. (Orgs.) Solos da Cidade de São Paulo. São Paulo, Associação Brasileira de Mecânica dos Solos e Associação Brasileira de Engenharia de Fundações: 37-94.

STASKI, E.

2002 Urban archaeology. Orser, Ch.O.Jr. (Org.) Encyclopedia of historical archaeology. Londres/N. York, Routledge: 546-549.

VARGAS, M.

1992 Evolução dos Conhecimentos. In: Negro Jr., A.; Ferreira, A.A.; Alonso, U.R.; Luz, P.A.C. (Orgs.) Solos da Cidade de São Paulo. São Paulo, Associação Brasileira de Mecânica dos Solos e Associação Brasileira de Engenharia de Fundações: 1-36. 